\title{
Info-Convergence Ceramic Nanosystems
}

\author{
Wenji Jin**** and Dae-Hwan Park (10)*; \\ *Department of Nano Materials Science and Engineering, Kyungnam University, Changwon 51767, Korea \\ **College of Chemistry and Environmental Engineering, Jiujiang University, Jiujiang Jiangxi 332005, P. R. China
}

(Received June 1, 2019; Revised July 9, 2019; Accepted July 9, 2019)

\begin{abstract}
We face many fascinating and diverse challenges, the most important among which is to determine how to store a large amount of information with novel approaches. Info-convergence ceramic nanosystems, which combine ceramic materials science and information technology, may provide an attractive alternative. This review considers recent multidisciplinary advances in the development of info-convergence nanosystems based on ceramic materials and discusses various strategies under ceramic-based information systems with a special focus on materials and nanohybridization technologies. Ceramic materials have played diverse roles not only as the generic coding support, but also as the central coding substance. The review highlights the ceramic nanohybrid bio code and ceramic nanoparticle optical code for applications in tracking-and-traceability management, nano-forensics, anticounterfeiting, and even communication, as well as the four steps of encoding, encrypting, decrypting, and decoding for the desired applications. Additionally, associated challenges, potential solutions, and perspectives for future developments in the field are discussed.
\end{abstract}

\section{Key words : Info-convergence, Ceramic, Nanosystem, Bio code, Optical code}

\section{Introduction}

$\mathrm{C}$ eramic nanosystems have attracted tremendous research interest for their unique physicochemical properties, such as optical, magnetic, and electronic functionalities. ${ }^{1,2)}$ Advanced synthetic nanotechniques have improved chemical inertness and heat resistance at the molecular level and have provided unprecedented optical activity for tunable multi-colors by accurately controlling the particle size, composition, and morphology of ceramic nanomaterials. Recent progress in ceramic nanosystems has led to innovations in fields combining biomedicine, energy, the environment, and even information technology. ${ }^{3-9)}$

In recent decades, globalization has evolved at an exponential pace due to the digital revolution and rapid advances in various technologies that have led to an increase in the quantity of digital information. ${ }^{10)}$ As a result, the requirement of a code system has emerged that can carry a high density of information and allows reliability, integrity, authenticity, and confidentiality in data processing. As the material size can be controlled down to the nanoscale in engineered information nanosystems, invisible nano codes cannot easily be copied and are difficult to detect for counterfeiting. Furthermore, selectively modified ceramic nanomaterials are being used with nano-bio-info-cogno (NBIC)

Corresponding author : Dae-Hwan Park

E-mail : dhpark@kyungnam.ac.kr

Tel : +82-55-249-6432 Fax : +82-55-249-6432

ORCID

https://orcid.org/0000-0002-5922-2009 science. ${ }^{11)}$ This convergence can provide a strategic vision for next-generation information storage. ${ }^{3,12-15)}$

Based on their role in construction, ceramic materials may be categorized into two classes. As a coding support, ceramic materials protect the information code against severe biological and physical environments, and nanosized ceramic hybrids enable cohesive coding components to be highly dispersed throughout diverse kinds of media. The encapsulation of deoxyribonucleic acid (DNA) strands within ceramics can solve problems inherent to naked DNA that impose limitations on using DNA as available nano codes. ${ }^{16-21)}$ In addition, the stabilization of phase change nanoparticles within a non-melting ceramic, such as silica shells, exemplifies the capabilities of ceramics as supporting materials for a code system. ${ }^{22,23)} \mathrm{A}$ covert thermal coding system can be prepared based on solid-to-liquid phase change nanoparticles. The coding capacity depends on the nanoparticle composition. The silica shells protect metal cores from leakage and coalescence for a long time, and the unique thermal behaviors of the coding system are reproducible several times even at high temperatures.

On the other hand, as a coding substance, ceramic nanoparticles have been imparted designable physicochemical behaviors with the advent of nanotechniques. The characteristic optical properties provide ceramic nanoparticles with unparalleled capabilities. Upconversion nanoparticles, ${ }^{24-28)}$ quantum dots (QDs), ${ }^{29-32)}$ and photonic crystals ${ }^{33,34)}$ have been studied extensively for optical encoding. A number of researchers have shown interestA number of researchers have shown interestA number of researchers have shown interestLanthanide-doped upconversion nanoparti- 
Table 1. Brief Comparison of Current Info-Convergence Ceramic Nanosystems

\begin{tabular}{|c|c|c|c|c|}
\hline $\begin{array}{l}\text { Role of ceramic } \\
\text { materials }\end{array}$ & Coding component & Encoding element & Decoding & References \\
\hline \multirow[t]{2}{*}{ Coding support } & synthetic DNA & base $(\mathrm{A}, \mathrm{T}, \mathrm{C}, \mathrm{G})$ & $\begin{array}{c}\text { DNA sequencer, } \\
\text { binary (on/off) symbol image, } \\
\text { alphanumeric message }\end{array}$ & $\begin{array}{l}2,3,5,12,13 \\
15,16,18-21 \\
35-39\end{array}$ \\
\hline & nanoparticle & $\begin{array}{l}\text { solid-to-liquid phase } \\
\text { change }\end{array}$ & $\begin{array}{c}\text { differential scanning calorimetry, } \\
\text { infra-red camera }\end{array}$ & 22,23 \\
\hline \multirow[t]{3}{*}{ Coding substance } & $\begin{array}{l}\text { upconversion } \\
\text { nanocrystal }\end{array}$ & wavelength, intensity & $\begin{array}{l}\text { fluorescence microscopy and } \\
\text { spectroscopy }\end{array}$ & $\begin{array}{l}14,24-28 \\
57-61\end{array}$ \\
\hline & quantum dot & wavelength, intensity & $\begin{array}{l}\text { fluorescence microscopy and } \\
\text { spectroscopy }\end{array}$ & $29-32$ \\
\hline & photonic crystal & structural color & $\begin{array}{l}\text { reflection spectroscopy, optical } \\
\text { microscope in reflection mode }\end{array}$ & 33,34 \\
\hline
\end{tabular}

cles have been shown to convert near-infrared (NIR) incident light into higher-energy ultraviolet or visible emissions. In QD encoding, tunability can be achieved by changing the particle size or composition, thereby generating multiplex codes. Photonic crystals can be designed by modulating their refractive indices, lattice constants, or spatial symmetries, resulting in photonic bandgap properties. Light energy falling in the bandgap is reflected, generating different structural color codes. Based on the discussion above, a brief comparison of the current info-convergence ceramic nanosystems is summarized in Table 1.

Considering the extensive research on info-convergence ceramic nanosystems, we focus here on recent developments in the field of ceramic bio codes, in which ceramic nanohybrids act as the coding support, and on the intuitive ceramic upconversion codes, in which ceramic nanoparticles are used as the coding substance. This review presents various strategies to prepare ceramic-based nano coding systems along with an overview of their emerging applications.

\section{Ceramic Nanohybrids with DNA for Bio Code}

DNA is a long-term repository of genetic information dating back to millions of years. As nature's method of storing information, DNA has many potential advantages, such as a high information density, long-term memory for millennia even under nonideal conditions, and globally high reliability using four base $(A=T, C \equiv G)$ DNA sequences. ${ }^{35-39)}$ The possibility of information storage in DNA was first demonstrated in $1988{ }^{40)}$ Since then, DNA sequences have been artificially engineered and DNA-related technologies have been established; ${ }^{41)}$ consequently, DNA bio codes for a wide variety of applications have been further developed into next-generation information storage solutions.

However, compared to traditional storage methods (based on optics or magnetics), information stability remains a formidable challenge. When DNA is used as a code system to write, store, carry, and retrieve information outside living organisms, it can get severely damaged due to biological, chemical, and physical degradation. One possible solution is protecting the DNA code by nanohybridization with ceramic nanoparticles in order to produce a stable nanosystem. ${ }^{42-46)}$ These encapsulated DNA nanosystems are suitable for code systems. First, they are stable enough to endure severe environments and can maintain information integrity during storage and circulation. Second, the prepared DNA-ceramic nanocapsule can be applied to tangible products. Finally, timed and on-demand recovery of messages is possible by selectively removing encapsulating nanomaterials and collecting the code units of the DNA strands with appropriate methods.

A DNA bio code can be reliably deciphered using a global criterion, and the sequence encoding can be interpreted by a digit algorithm with logical data processing. Choy et al. designed the Avatar DNA that identifies DNA information using a mobile device, which helped combine this system with NBIC science for identification and communication (Fig. 1A)..$^{3,47-49)}$ DNA nanohybrids are emerging as ideal strategies for a variety of applications using multidisciplinary NBIC convergence.

In this section, we focus on a sufficiently stable DNA@ ceramic bio code based on DNA@silica and DNA@layered double hydroxide (LDH) nanohybrids. In particular, we will describe chemical and hybridization methods, as well as encoding/decoding strategies associated with the applications of the DNA@ceramic nanohybrid bio code.

\subsection{Design and synthesis of DNA@ceramic nanohy-} brids

Grass and coworkers have developed synthetic DNA "fossils", mimicking the inherent hermetic diffusion barrier of fossils. ${ }^{17,19,46)}$ DNA was encapsulated into amorphous silica instead of "natural" amber (polymerized terpenes). Silica is a ceramic material with high melting point as well as exceptional barrier property. It can be both synthesized and disintegrated at room temperature under appropriate chemical conditions. Considering the characteristics presented above, silica is an ideal material for an encapsulation-release system to achieve the DNA code system.

Figure 2A(a) illustrates the method for encapsulating DNA molecules into amorphous silica spheres to form 

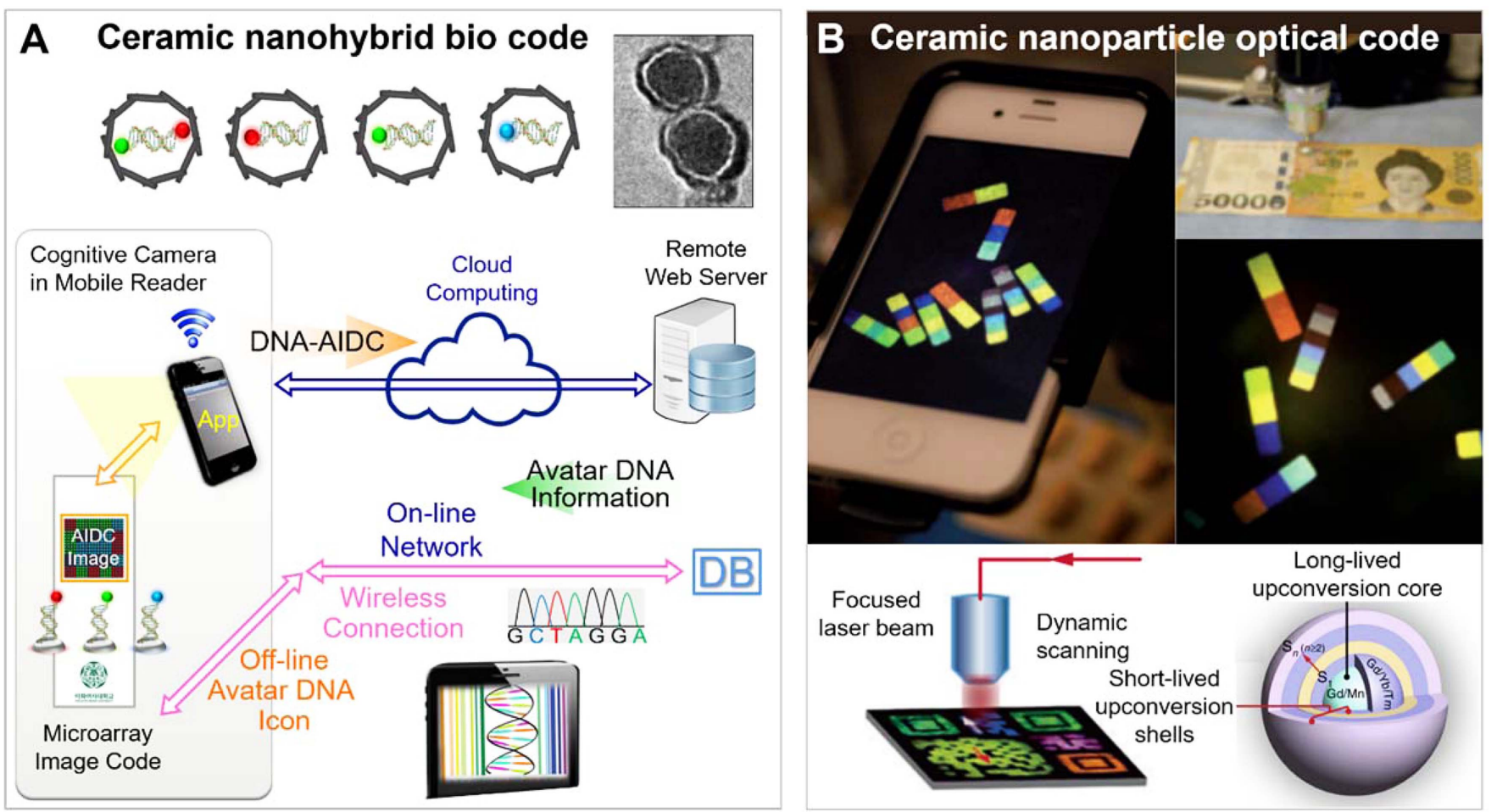

Fig. 1. A. Schematic illustration of the Avatar DNA nanohybrid system, structure design, and cross-section TEM image of the DNA@LDH core-shell structured hybrids, reproduced from ref. [3] B. Multicolored barcodes by micropatterning through upconversion nanoparticle-encapsulated polymeric microparticles (top), reproduced from ref. [14] and multilevel anti-counterfeiting through $\mathrm{Mn}^{2+}$-activated upconversion nanoparticles (bottom), reproduced from ref. [27]

reversible three-dimensional (3D) DNA@ $\mathrm{SiO}_{2}$ hybrids. The encapsulation comprises the following procedures: $1 . \mathrm{SiO}_{2}$ particle preparation, 2. ammonium functionalization of $\mathrm{SiO}_{2}$ particles, and 3. DNA encapsulation. The prepared silica particles are functionalized through a reaction with N-trimethoxylsilylpropyl-N,N,N-trimethylammonium chloride (TMAPS) to carry positive surface charges as $\mathrm{NH}^{+}$. During encapsulation, DNA is adsorbed onto positively charged support particles and a $12-15 \mathrm{~nm}$ thin silica layer is formed as a top layer via polycondensation of tetraethoxysilane (TEOS) through the sol-gel process. The structural features of the prepared DNA@ $\mathrm{SiO}_{2}$ were revealed by TEM analysis (Fig. 2B(a)). ${ }^{17,19)}$

In the case of DNA@ $\mathrm{SiO}_{2}$, DNA molecules are hermetically sealed within the glass spheres and protected from chemical and physical attack to form stable "synthetic fossils". If shielded from light, the encapsulated DNA@ $\mathrm{SiO}_{2}$ nanohybrids can be stored safely at room temperature. For further analysis of the protective properties of the encapsulation particles, they are treated with radical oxygen species (ROS) for $10 \mathrm{~min}$, for which the protection efficiency should be $>90 \%$ (Fig. 3A). From the sequencing chromatograms, the cipher DNA released from DNA@ $\mathrm{SiO}_{2}$ nanohybrid even after temperature-treated at $120^{\circ} \mathrm{C}$ for $15 \mathrm{~min}$ showed the same results as that of the original DNA strands. The thermal stability can be demonstrated through the analysis presented above.
For practical application as a code system for information storage, DNA molecules are required to be released from theencapsulates and retrieved without harm for the decoding process. The DNA code can be recovered from the glass spheres without damage using fluoride-containing buffered oxide etch solutions. After dissolution of the spheres and purification, the DNA codes can be analyzed by standard techniques including gel electrophoresis, sequencing, and the quantitative polymerase chain reaction (qPCR).

LDHs, which are also well known as anionic clays, are represented as a two-dimensional (2D) layered crystal structure with a general chemical formula of $\left[\mathrm{M}^{2+}{ }_{1-\mathrm{x}} \mathrm{M}^{3+}{ }_{\mathrm{x}}(\mathrm{OH})_{2}\right]$ $\left(\mathrm{A}^{\mathrm{m}-}\right)_{\mathrm{x} / \mathrm{m}} \cdot \mathrm{nH}_{2} \mathrm{O}$, where $\mathrm{M}^{\mathrm{n}+}$ is a metal cation and $\mathrm{A}^{\mathrm{m}-}$ represents an interlayer anion. $\mathrm{LDH}$ s are composed of cationic metal hydroxide host nanosheets, where some of the $\mathrm{M}^{2+}$ sites are partially substituted with isomorphic $\mathrm{M}^{3+}$ ions, in order for the host layer to acquire a positive charge. In order to satisfy the charge neutrality condition, exchangeable anionic species should be stabilized in the interlayer spaces of LDH hosts. LDHs are ideal materials for hybrids owing to their advantages such as variable chemical compositions, anion-exchange capacity, host-guest interactions, crystallization dissolution characters, and biocompatibility. ${ }^{50-55)}$

Negatively charged DNA molecules are immobilized inside the positively charged LDH matrix to achieve a stable DNA-LDH nanohybrid system. The intercalation chemistry for DNA-LDH nanohybrids was proposed for the first 
A

(a)
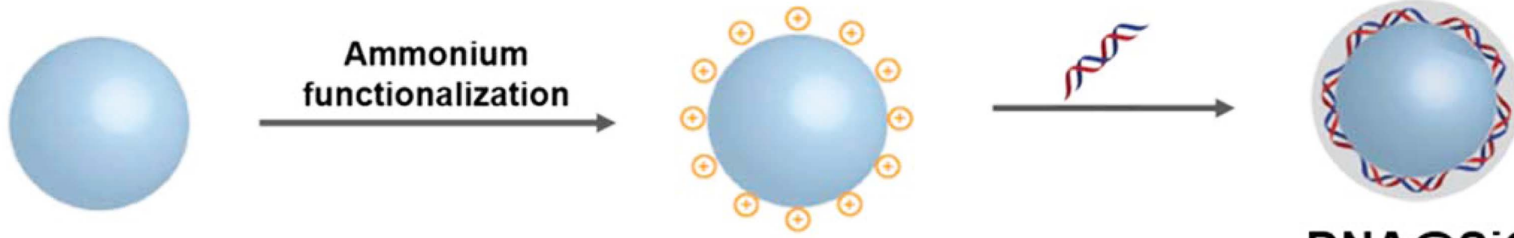

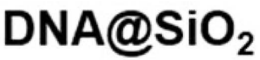

(b)
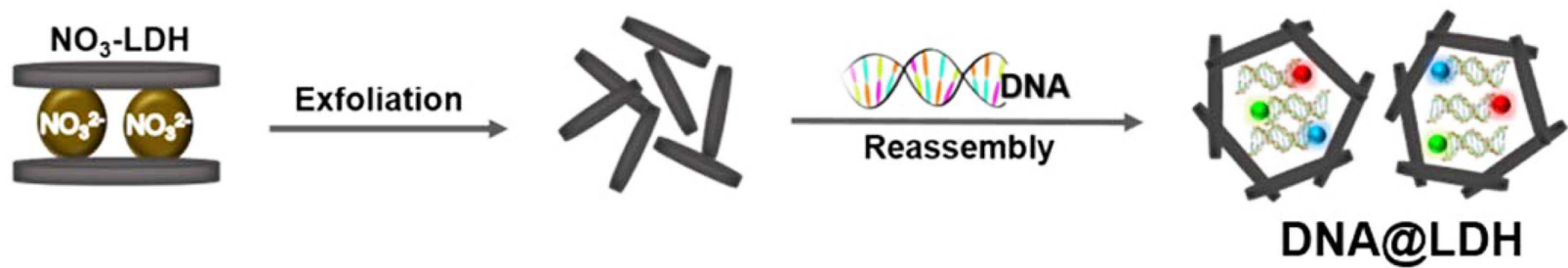

B

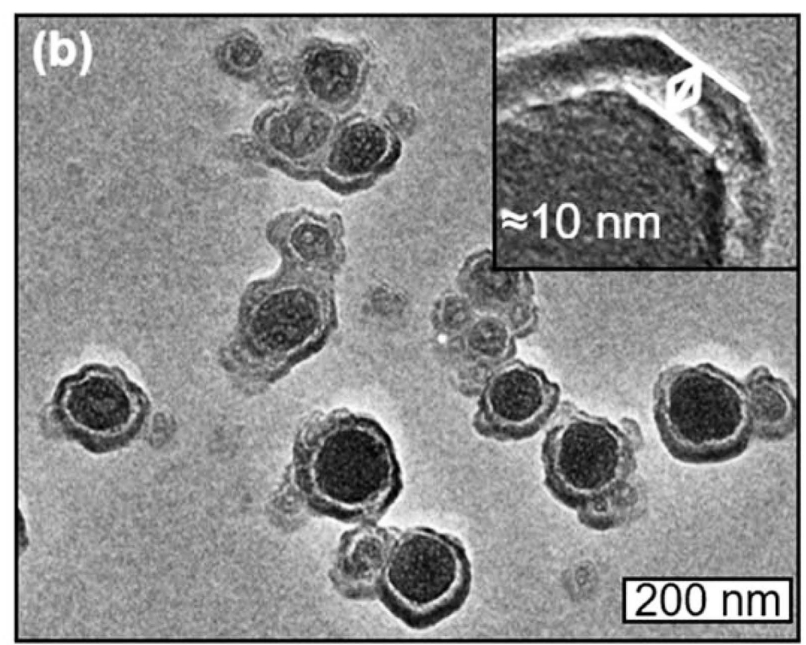

Fig. 2. A. Encapsulating routes and B. transmission electron microscopy (TEM) image of (a) DNA@SiO ${ }_{2}$, (b) DNA@LDH core shell, reproduced from ref. [5, 17, 19].

time in 1999 as "bioinorganic nanohybrids". ${ }^{6}$ In 2004, pioneering studies on DNA-LDH hybrids for information storage were conducted by Choy et al. ${ }^{16)}$ The typical 2D layered DNA/LDH hybrids were prepared by an anion-exchange route and demonstrated their applicability as a genetic molecular code system.

For bulky and large molecules, the above encapsulation method often results in low availability because anion adsorption to the LDH surface is restricted by physical limits on lattice expansion. As shown in Fig. 2A(b), a new approach termed "exfoliation-reassembly" provided a synthetic pathway to stabilize the DNA code inside a spherical core, reassembled with $\mathrm{LDH}$ single nanosheets, to form a 3D DNA@LDH core-shell. ${ }^{5}$ A nitrate-intercalated LDH was prepared first, then delaminated into single $\left[\mathrm{Mg}_{2} \mathrm{Al}(\mathrm{OH})_{2}\right]^{+}$ nanosheets in a suitable solvent. The colloid of exfoliated LDH single sheets was then blended with the aqueous solution of DNA, where $\mathrm{LDH}$ nanosheets were utilized as a building block and DNA as a charge-balancing anion guest species. The electrostatic interactions resulted in self-reassembly to achieve a chemically well-defined and uniformly spherical DNA@LDH nanocapsule. The features of the pre- pared DNA@LDH core-shell structured hybrids were revealed using TEM analysis (Fig. 2B(b)).

With respect to DNA@LDH, in the first encoding step, a sequence-manipulated double-stranded DNA (dsDNA) of a 35-base-pair duplex conjugated with green-color $\mathrm{Cy} 3$ or redcolor Cy5 fluorophore was designed as a molecular tracer. In the second encrypting step, the designed DNA code was encapsulated in the core space of the $\mathrm{LDH}$ nanoshell with an overall thickness of $\approx 10 \mathrm{~nm}$ to produce a DNA@LDH bio code with a particle size of $\approx 100 \mathrm{~nm}$. It is suitable for applying the bio code into various products. The LDH surface can be modified easily, and it is possible to apply the nano code in hydrophobic fluidic systems. In the third decrypting step, a small amount of DNA@LDH nanoparticles was collected, and DNA strands inside the LDH layers were safely released upon the $\mathrm{pH}$-dependent dissolution of LDH. These can then be recovered through appropriate methods (e.g., magnetic separation) for analysis. In the final decoding step, DNA or the PCR product after amplification could be identified by DNA-chip assays or gel electrophoresis.

Stabilization of the DNA codes within the nanosized LDH matrix is one of the most important abilities for identifica- 


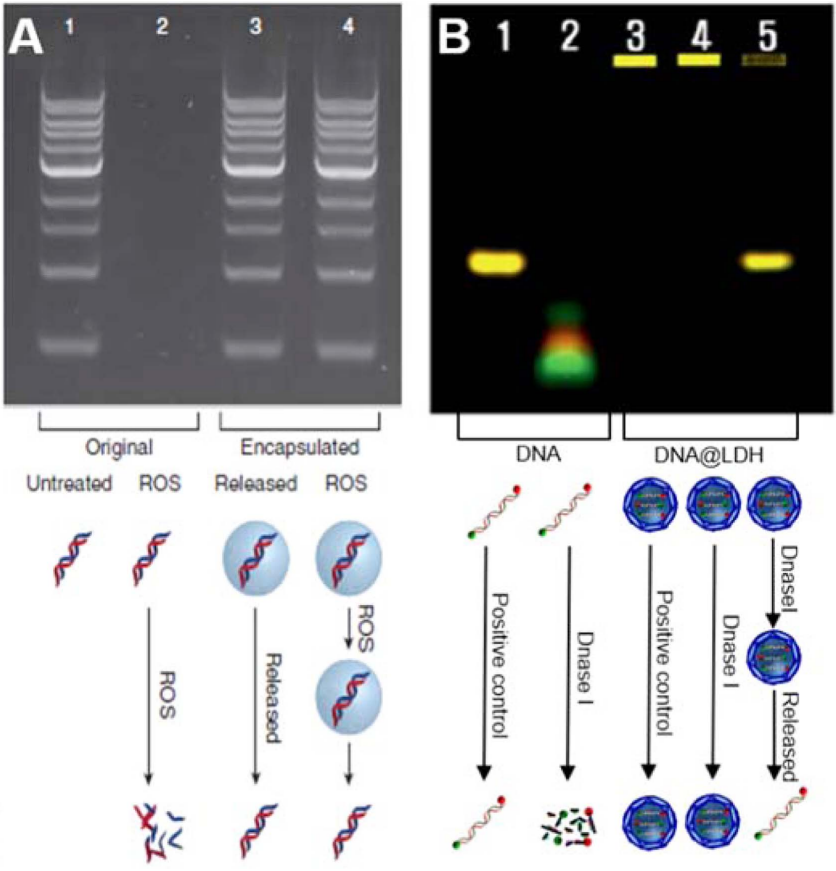

Fig. 3. Stability evaluation: gel electrophoresis result of A. free designed DNA and DNA@ $\mathrm{SiO}_{2}$ against ROS activity, B. free designed DNA and DNA@LDH against enzymatic condition, reproduced from ref. $[17,5]$ tion systems. The results of a thermal stability test, which detects melting points and chemical stability against copper-catalyzed DNA damage, showed the superior protection ability of DNA@LDH nanohybrids. In addition, stability against enzymatic damage is the most significant benefit of DNA@LDH hybridization. As shown in Fig. 3B, even after treatment with DNase I, a kind of ribonuclease, both the DNA released from LDH and the free DNA exhibited the same electrophoretic mobility. This provided convincing evidence that the structural features of DNA were fully protected from DNase I treatment.

Combining the strategies presented above, both DNA@ $\mathrm{SiO}_{2}$ and DNA@LDH bio codes ensure a high level of identification and provide advanced information storage with confidentiality and inherently high security.

\subsection{DNA@SiO $\mathrm{S}_{2}$ nanohybrids for tagging and label- ling technology}

Global counterfeiting and adulteration extend to all types of products, especially high-profit and high-volume merchandise. Fuels, high-value cosmetic products, medicines, foodstuffs, and even food are routinely counterfeited for large illegitimate profits. This causes serious societal instabilities, e.g., large monetary losses for governments or a great threat to consumer health. Determining the authen-

A (a)

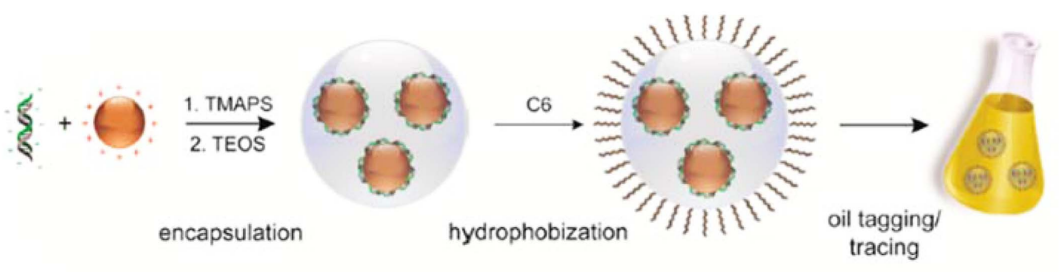

(c)

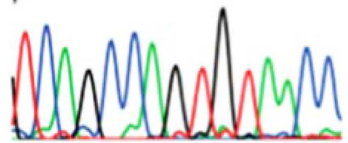

(b)
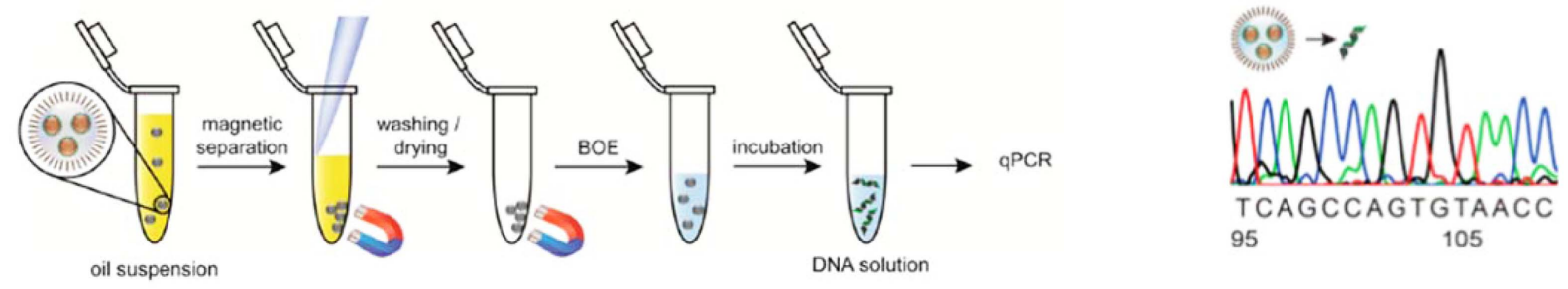

B (a)

(b)
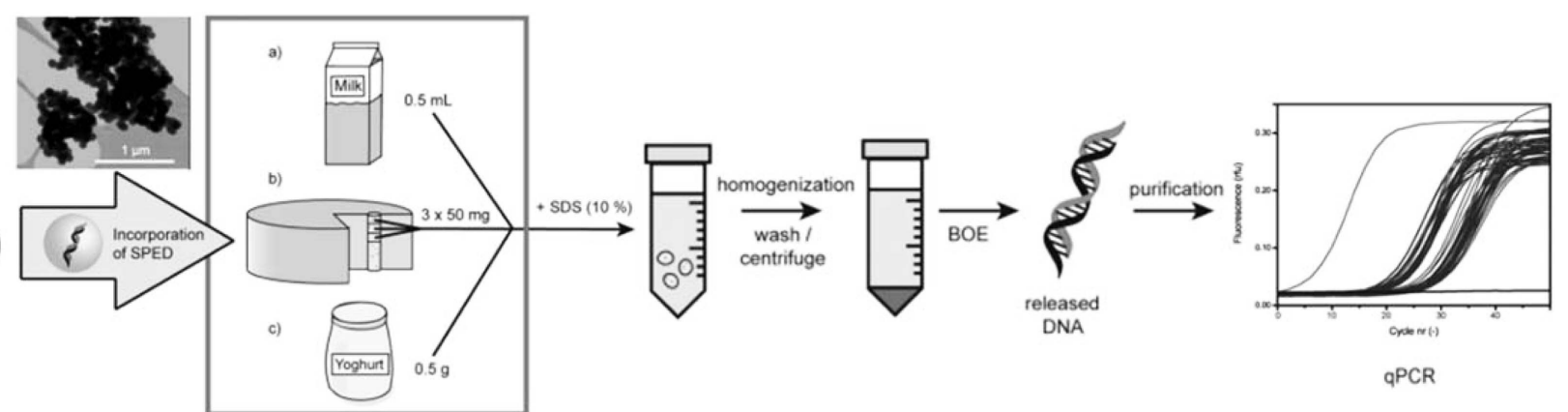

Fig. 4. A. (a) Synthesis of $\mathrm{Fe}_{2} \mathrm{O}_{3} / \mathrm{TMAPS} / \mathrm{DNA} / \mathrm{SiO}_{2}$-C6 particles, (b) analytic route of DNA recovery from oil particle suspensions and subsequent quantification by qPCR, (c) sequencing chromatograms of base 95-109 of unprocessed dsDNA sequence (top panel) and encapsulated/recovered from decalin (bottom panel), reproduced from ref. [20] B. (a) Characteristic electron microscopy image of DNA@SiO ${ }_{2}$, (b) flowchart for incorporation of DNA@SiO ${ }_{2}$ into milk, cheese, and yoghurt and subsequent extraction of the marker from the foodstuff by washing/centrifugation procedures for final analysis via qPCR, reproduced from ref. [21] 
ticity of products is fundamental for both consumer health and trader interests.

Grass et al. have proposed methods for oil authentication and tracing a food product along its production chain. In 2014, they applied silica particles with encapsulated DNA (SPED) as both, invisible oil tags and unique food tracers. ${ }^{20-21)}$ Silica particles have long been used as food additives (E551), and there is immense potential for applying the SPED tracer to various food types.

A successful application of the SPED tagging/tracing technology in three model oils, a fuel oil (gasoline), a food-grade oil (extra virgin olive oil), and a therapeutic oil (bergamot oil) has already been demonstrated. A thermostable, hydrophobic, and magnetic DNA@ $\mathrm{SiO}_{2}\left(\mathrm{Fe}_{2} \mathrm{O}_{3} / \mathrm{TMAPS} / \mathrm{DNA} / \mathrm{SiO}_{2}-\right.$ C6) particle has been developed for use as an invisible tag for oil products. The barcode function of the inert taggants was used in order to prove the authenticity of the oil-based items.

For encoding, dsDNA of $\approx 100$ base pairs was purchased by Microsynth AG. In the encrypting step, $\mathrm{Fe}_{2} \mathrm{O}_{3}$ /TMAPS/ $\mathrm{DNA} / \mathrm{SiO}_{2}$-C6 particles were synthetized, with a core-shell structure and consisting of magnetically recoverable nanoengineered shells embedding artificial DNA sequences (Fig. $4 \mathrm{~A}(\mathrm{a})) . \mathrm{Fe}_{2} \mathrm{O}_{3}$ nanoparticles were synthetized by an inexpensive synthesis method based on co-precipitation and were then further functionalized with ammonium groups using TMAPS. DNA molecules were adsorbed on the prepared magnetic particles, and the $\mathrm{Fe}_{2} \mathrm{O}_{3}$ /TMAPS/DNA nanocluster was coated with a dense $\mathrm{SiO}_{2}$ layer using TEOS as the $\mathrm{Si}$ source via sol-gel chemistry. The silica surface was further functionalized by hydrolysis of N-hexyltrimethoxysilane to achieve dispersibility in hydrophobic fluids. The hydrodynamic particle size of the obtained nanoengineered encapsulate distribution in toluene was $\approx 135 \mathrm{~nm}$, and the tags did not affect the optical properties of the dispersant at concentrations below $103 \mu \mathrm{g} / \mathrm{L}$. The thermal stability of DNA encapsulated within the particles was demonstrated in comparison to unprotected DNA. The taggants could still be detected after being treated at $160^{\circ} \mathrm{C}$ for $30 \mathrm{~min}$, while naked DNA was no longer detectable after being heated in water to $120^{\circ} \mathrm{C}$. The additional test for long-term storage capability also showed the good stability of the prepared materials in decalin at room temperature for durations of up to 2 years.

Encrypting is the key process for tagging (Fig. 4A(b)). Therefore, it is important to collect $\mathrm{Fe}_{2} \mathrm{O}_{3}$ /TMAPS/DNA/ $\mathrm{SiO}_{2}$-C6 particles from oils efficiently and recover the DNA from encapsulates without damage. Using magnetic separation, even low concentrations of particles (down to $1 \mu \mathrm{g} / \mathrm{L}$ ) and low volumes $(1 \mathrm{~mL})$ could be collected from oil systems for further treatment. Both the $\mathrm{Fe}_{2} \mathrm{O}_{3}$ and $\mathrm{SiO}_{2}$ matrix can be dissolved in buffered oxide etch (BOE) solution. The recovered DNA molecules were analyzed by qPCR or Sanger sequencing for decoding (Fig. 4A(c)). The novel magnetic DNA@ $\mathrm{SiO}_{2}$ particles can be utilized as low-cost $\left(2 \times 10^{-4}\right.$ USD/L) tracers, and the method is universal for a variety of oils and oil-derived products.

The inert taggants, which have stable core-shell structures, were composed of an iron oxide core and a protective silica layer. Each of the ceramic materials plays a significant role in the encapsulates, in which the $\mathrm{Fe}_{2} \mathrm{O}_{3}$ core confers the magnetic properties for separation, allows for sample concentration, and facilitates handling, while the surrounding $\mathrm{SiO}_{2}$ matrix can act as hermetical sealing layer and is responsible for heat stability, surface functionality, as well as recoverability for the DNA tags.

The SPED were also developed as food tracers to a milk processing chain (Fig. 4B). The food labelling technology along its production chain is essential to ensure product authenticity and food safety. Both synthetic (MB1) and naturally occurring (TOM1) DNA sequences were utilized as DNA codes. The SPED were prepared by the approach introduced in Section 2-1 and the stability of the DNA code protected within SPED was demonstrated. In this study, the developed particles were added to milk, as well as milkderived yoghurt and cheese. Following extraction of the tags

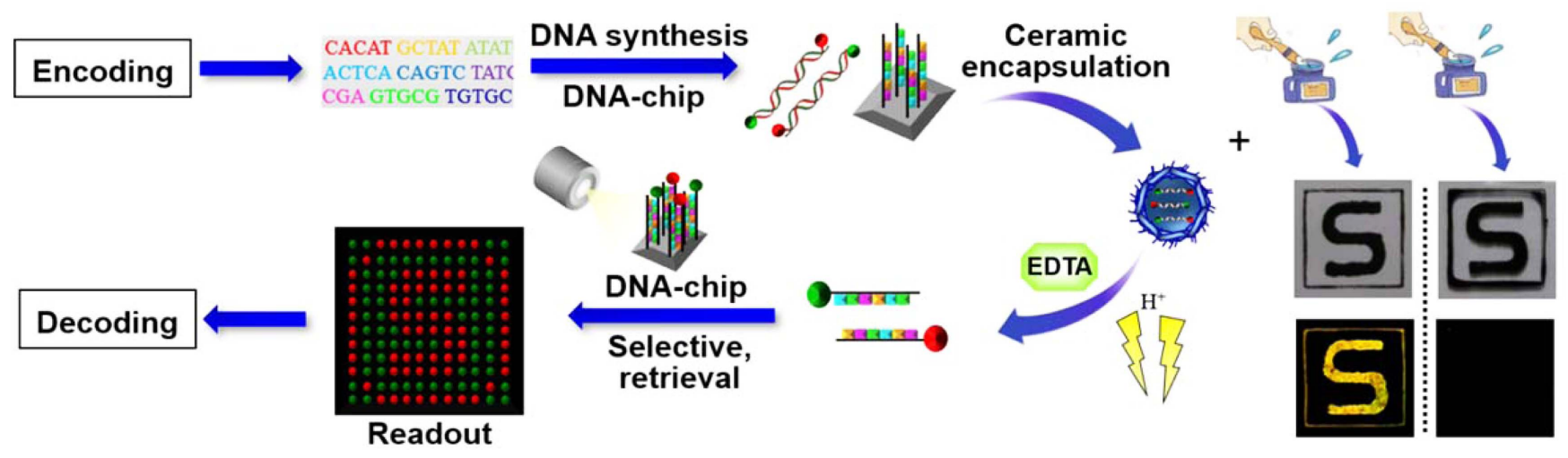

Fig. 5. Nano-forensics based on a DNA@LDH. Schematic illustration for encapsulating the forensic DNA to prepare DNA@LDH and mix with commercial black ink, top: photograph images of the [S] marking by pure ink (right) and by DNA@LDH ink (left), bottom: fluorescence microscopy images, schematic procedure for authentication of the forensic DNA from the [S] marking mixed with DNA@LDH by DNA-chip binding under illumination, readout images of the graphic [S], reproduced from ref. [5] 
from the food matrix, upon mixing with BOE solutions, the silica layer can be dissolved and the released unique DNA code could sufficiently be quantified via quantitative $q P C R$ at tracer concentrations as low as $0.1 \mathrm{ppb}$ ( $\mu \mathrm{g}$ per $\mathrm{kg}$ milk). The results have demonstrated the potential of SPED as a sufficiently stable and precise food tracer.

\subsection{DNA@LDH nanohybrids for nano-forensics}

The DNA@LDH core-shell structured hybrid, which is one of the DNA@ceramic steganographies introduced in Section 2.1 , can be used as a highly specific molecular coding system. DNA@LDH nanoshells were developed by Choy et al. in $2010 .^{5)}$ The LDH ceramic shell plays an important role in the system to provide efficient protection for DNA code, robust support during data processing in various kinds of media, as well as on-demand de-capsulation. DNA@LDH bio codes have received more attention due to the advan- tages of LDH in identification systems including highly precise nano-forensics. A completely new convergence science, called "nano-forensics", has developed with advanced nanotechnology merged with forensic science. In nano-forensics, nanoparticulate traces are utilized to investigate issues such as the adulteration of chemical products, document copyright counterfeiting, drug trafficking, terrorists, and so on.

As a proof-of-concept, the authors validated that the DNA@LDH nanohybrid was sufficiently useful in a DNAbased document authentication system (Fig. 5). A security element [S]-shaped signature was printed on a glass slide with a nanohybrid-suspended black ink prepared by integrating the DNA@LDH nanohybrid into conventional ink. The DNA@LDH nano-forensics molecules were created through the strategy described in section 2.1. Although both [S] characters printed with the nanohybrid-formulated ink

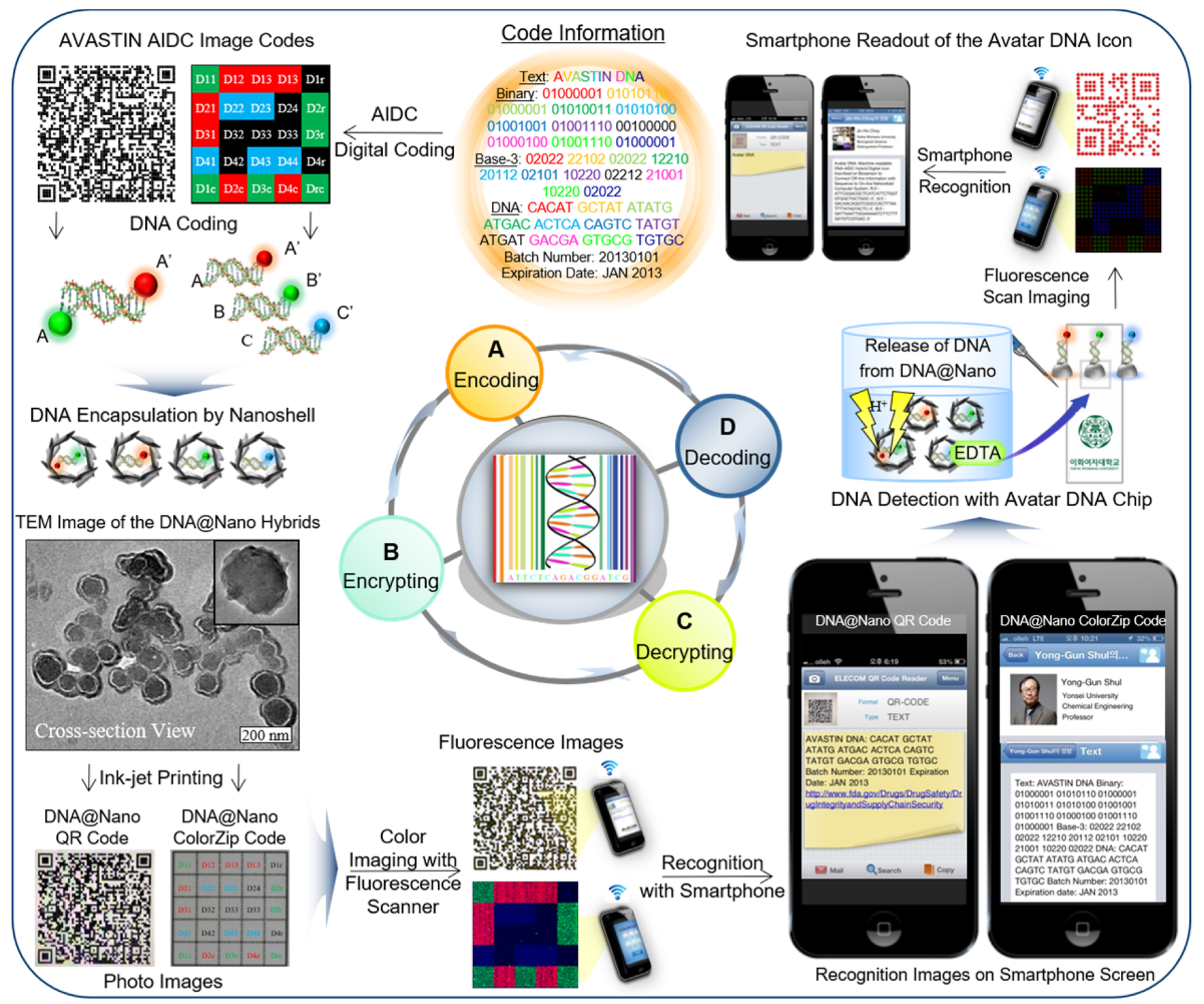

Fig. 6. Avatar DNA systems with NBIC convergence during proof-of-concept workflow on drug integrity and supply-chain security presented by four basic data processing steps: encoding, encrypting, decrypting, and decoding, reproduced from ref. [3] 
and pure ink look the same to the naked eye, one can differentiate the secured forensic [S] character from the nonforensic [S] character by fluorescence analysis. The nanohybridsuspended [S] marking shows yellow-merged green and red fluorophores labeled in the designed DNA code. For further accurate identification of base sequences, the DNA molecules were decrypted from the [S] signature by resolving the LDH shell in a slightly acidic solution $(\mathrm{pH}=4)$, along with the addition of EDTA, a chelating agent for trapping $\mathrm{Mg}^{2+}$ and $\mathrm{Al}^{3+}$ ions. The released forensic DNA code was collected and then detected by the microarray. The DNA-chip $(12 \times$ 12 array, 144 spots) could be pre-patterned as the [S] shape in green/red, in which each spot was designed with complementary sequences to those in DNA@LDH. The released dsDNA from the hybrid was denatured to single strands after heating at $95^{\circ} \mathrm{C}$ for $2 \mathrm{~min}$, which were detected by DNA-chip hybridization in one second. Hence, the security DNA information was successfully identified as an [S] graphic of representative spots.

\subsection{AvatarDNA@ceramic nanohybrids for NBIC convergence}

More recently, Choy et al. combined the above mentioned methods in the DNA@LDH nanohybrid bio code with an electrical mobile smartphone device to suggest a new concept called "Avatar DNA", as illustrated in Fig. 1A. ${ }^{3)}$

Avatar DNA is an optical machine-readable icon on a DNA biosensor for automatic identification and data capture (ADIC) in the form of Quick Response (QR) and ColorZip codes. Therefore, specific information encoded in a DNA base-sequence can be identified through a photographic scan from a smartphone, and can connect offline DNA image codes to online remote databases, including secret messages, indexes, profiles, and URLs.

As a proof-of-concept experiment, the Avatar DNA platform was applied to strengthen the supply-chain security of an injectable cancer medicine, Avastin. The comprehensive item-level identification system was elaborated by four steps: encoding, encrypting, decrypting, and decoding. In the encoding step, the secured AVASTIN DNA codes were encoded using binary coding via ASCII characters, the base3 Huffman-compression coding method and a practical DNA encoding method. The encoded information was expressed as a $2 \mathrm{D} \mathrm{QR}$ or $3 \mathrm{D}$ ColorZip code through a logical code algorithm (Fig. 6A). In the encrypting step, a DNA@LDH hybrid bio code was prepared as mentioned in Section 2.1, and artificial DNA molecules with red, green, and blue color fluorophores were encapsulated in $\mathrm{LDH}$ ceramic shells to produce a series of three differently colored nanohybrid-suspended inks. The DNA-QR code and the DNA-ColorZip code pattern were printed with the prepared nanohybrid-suspended inks in the form of a packaging label (Fig. 6B). In the decrypting step, fluorescent Avastin DNA-AIDC images were captured and read by scanning with a smartphone camera to display the hidden DNA codes on the screen. Thus, the users can check timely intermediate results by directly connecting offline DNA-AIDC tags with an online reference database. In the decoding step, the AVASTIN DNA molecules were collected by the routes described in Section 2.3, and DNA identification proceeded through hybridization on each DNA-chip. The resulting DNA-QR icon and DNA-ColorZip icon on the microarray were automatically identified by a smartphone with the required application, which can provide further information through wireless networking, namely the phone-based tele-info communication.

Therefore, the NBIC convergence strategy, in which each building block stands for ceramic nanosheets, nucleotides, digits, and pixels, could sufficiently verify the item-level identification that strengthens supply-chain security against counterfeits.

\section{Ceramic Nanoparticles with Upconversion for Optical Code}

Luminescent materials have been used in a broad range of fields, in particular, optical data storage and security codes for optical anti-counterfeiting. ${ }^{56)}$ Fluorescence color coding is one of the most popular methods for optical multiplexing. Despite its advantages, the capability of conventional fluorescent color coding is limited by background interference and spectral overlap.

Upconversion materials have been extensively researched due to their inherent abilities. ${ }^{57-59)}$ In contrast to commonly used QDs and organic fluorophores, upconversion nanoparticles typically consist of an inorganic host matrix and lanthanide dopants embedded in the host lattice. Photon upconversion is a nonlinear optical process, in which successive absorption of two or more low-energy photons is followed by luminescent emission of high-energy photons. Lanthanide-doped upconversion nanocrystals (UCNs) may provide a possible solution due to their unique optical properties, including large anti-Stokes shift, long luminescence lifetime, and distinguishable spectroscopic fingerprint. Despite the considerable achievements, upconversion nanomaterials have a limited capacity and the low quantum conversion efficiency for practical applications. Hence, researchers have been developing innovative solutions by controlling the composition of the nanocrystals and the structural configuration precisely during the synthesis. Indeed, there has been impressive progress over the past few years; for instance, Doyle et al. generated a unique encoding architecture that combines spatial micropatterning with UCNs and demonstrated large encoding capacities (Fig. 1B, top). ${ }^{14)}$ More recently, it was reported that in addition to lanthanide ions, transition metal ions such as $\mathrm{Mn}^{2+}$ which exhibit a long-lived emission decay, have been employed for lifetime-based anti-counterfeiting (Fig. 1B, bottom). ${ }^{27)}$

\subsection{Lifetime-based upconversion code}

Tuning of the lifetime is a method that utilizes the temporal domain of the luminescence. Fluorescence lifetime encoding with rare earth metals, which have a long lifetime 

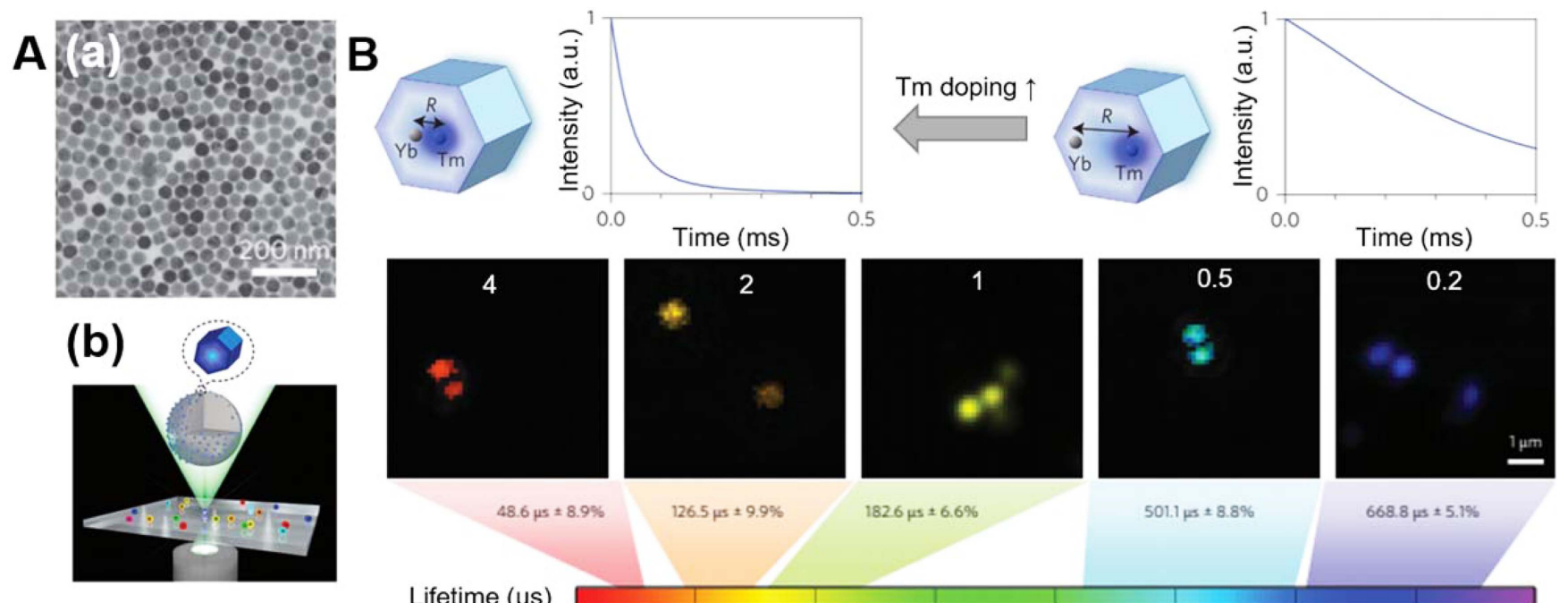

$126.5 \mu \mathrm{ss}=9.9 \%$

$1826 \mu=.6 .6 \%$

$501.1 \mathrm{ps} \pm 8.8 \%$

$668.8 \mathrm{ps}=5.1 \%$

Lifetime ( $\mu \mathrm{s})$

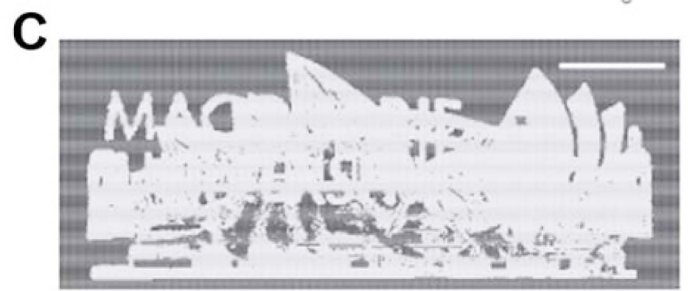

100

200
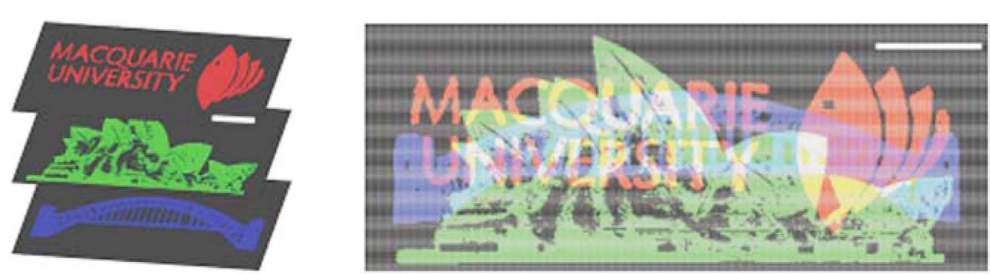

Fig. 7. A. Concept of $\tau$-dots-encoded microspheres as the lifetime multiplexing suspension arrays, (a) typical TEM image of the nanocrystals, (b) the synthesized monodispersed Tm upconversion nanocrystals can be embedded into the shell of porous microspheres, which can be decoded by the time-resolved scanning cytometry system, B. lifetime tuning scheme and time-resolved confocal images for $\mathrm{NaYF}_{4}: \mathrm{Yb}, \mathrm{Tm}$ upconversion nanocrystals, C. demonstration of lifetime-encoded document security and photonic data storage, reproduced from ref. [26]

ranging from micro to milliseconds, is preferred over organic dyes and QDs, which have shorter lifetimes (organic dyes $<10 \mathrm{~ns}$ and QDs: $10-100 \mathrm{~ns}) .{ }^{26,60)}$

Jin and coworkers have shown that tunable luminescent lifetimes, referred as " $\tau$-dots" in the microsecond region, could be utilized to code individual UCNs ${ }^{26)}$ In this study, energy transfer from the sensitizer $\mathrm{Yb}^{3+}$ to blue-emitting $\mathrm{Tm}^{3+}$ ion at changing sensitizer-emitter distances allowed lifetime tunability. As shown in Fig. 7B. by modulating the $\mathrm{Tm}^{3+}$ ion concentration between $4,2,1,0.5$, and $0.2 \mathrm{~mol} \%$ with a fixed $20 \mathrm{~mol} \%$ of $\mathrm{Yb}^{3+}$ ions in $40 \mathrm{~nm} \mathrm{NaYF} 4: \mathrm{Yb}, \mathrm{Tm}$ nanocrystals, the life time could be tuned from 48.6 to 668 us (Fig. 7B). $\mathrm{NaYF}_{4}: \mathrm{Yb}, \mathrm{Tm}$ nanocrystals were synthesized by the thermal decomposition to an average particle size of approximately $40 \mathrm{~nm}$ with a narrow size distribution (Fig. 7A). Eight distinct lifetime codes were prepared by a new temporal-domain approach, and more distinguishable codes could be produced by fine-tuning the co-doping ratio of $\mathrm{Yb} /$ Tm.

As a proof-of-concept, it was demonstrated that the purpose-engineered $\tau$-dots carrying lifetime codes can be used as barcodes in document security for anti-counterfeiting. Fig. 7C presents three overlaid images of the Macquarie University logo, Sydney Opera House, and Sydney Harbour Bridge, printed with $\tau$-dots-suspended commercial ink with $\mathrm{Yb}: \mathrm{Tm}$ doping concentration ratios of 20:4, 20:1, and 20:0.5 (mol\%), respectively. The overlapping patterns (left) printed with $\mathrm{NaYF}_{4}: \mathrm{Yb}$,Tm nanoparticles with three distinct lifetimes could be decoded (right) by time-resolved scanning cytometry with a $980 \mathrm{~nm}$ laser. Three individual images, the Macquarie University logo in red having a lifetime of 52 $\mu \mathrm{s}$, the Sydney Opera House in green having a lifetime of $159 \mu \mathrm{s}$, and the Sydney Harbour Bridge in blue having a lifetime of $455 \mu \mathrm{s}$, can be clearly observed. This result suggests a new type of document encryption with $\tau$-dots as security inks. The prepared nanocrystals have also been used to create a new matrix of $\tau$-dots-encoded microspheres as multiplexing suspension arrays.

\subsection{Encoding architecture with spatial micropat- terning of upconversion code}

When upconversion nanoparticles were used as an optical code for document security and anti-counterfeiting, the emission color was the basic security element, and was tunable from visible to NIR light. Increasing the number of emission colors and manipulation of morphology are both straightforward and efficient strategies for meeting the criteria for multilevel anti-counterfeiting applications.

Doyle and coworkers reported a robust encoding strategy that combined distinct UCNs with spatial patterning and the generated unique polymer microparticle barcodes exhibited high-density encoding (> $10^{6}$ particles) and an ultralow 
A

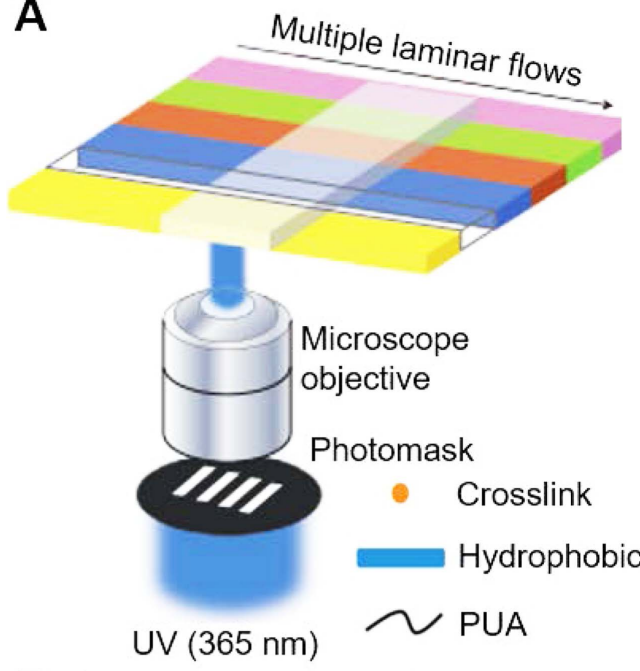

B
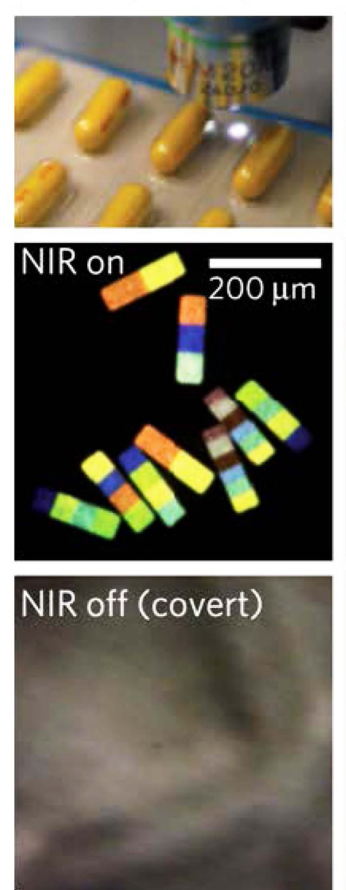
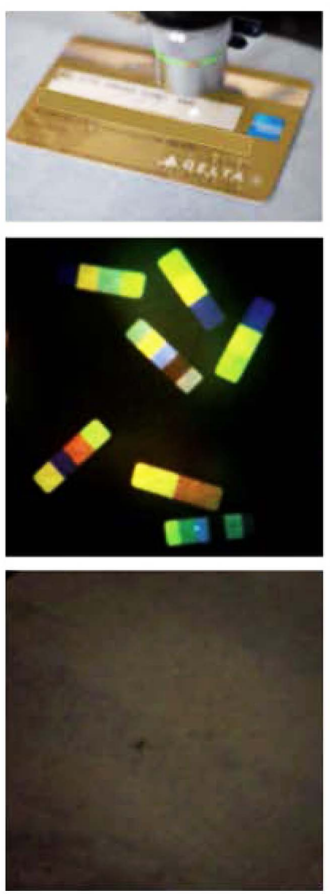

Surface encoding (PUA)
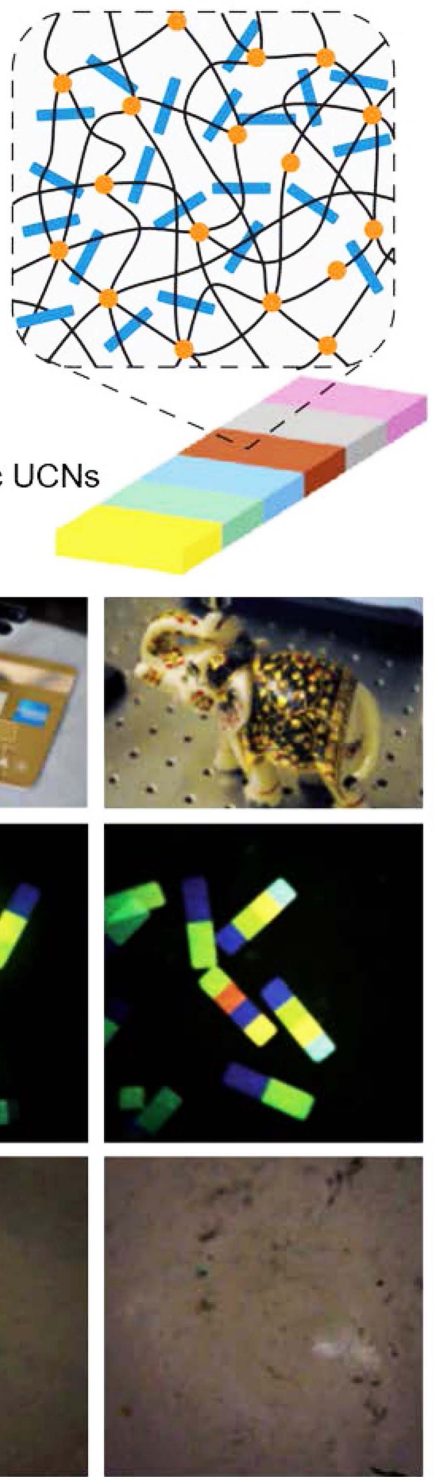
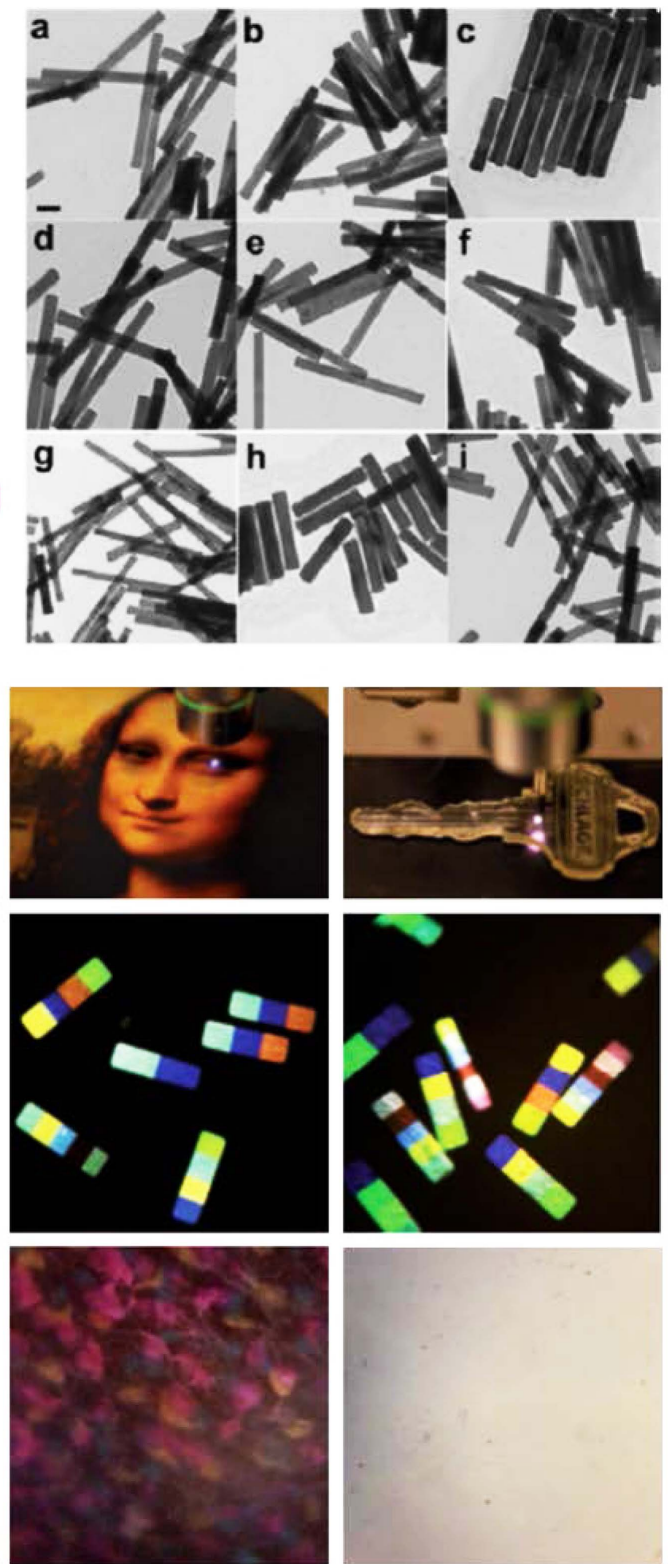
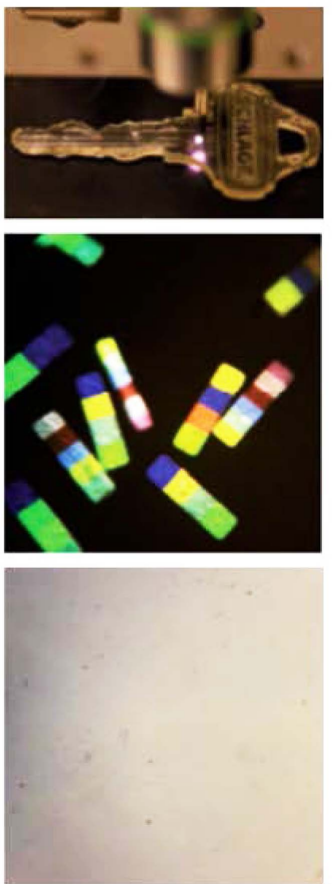

Fig. 8. A. Synthesis of encoded particles by stop-flow lithography. Multiple co-flows of monomer solution with UCNs were photopolymerized in a PDMS channel through illumination with photomask-patterned ultraviolet light (365 nm) (left). Hydrophobic UCNs are physically entrained in the tightly crosslinked PUA matrix (middle). TEM characterization of UCN1-9 doped with various concentrations of dopants (right). B. Imaging of encoded particles with portable decoder in challenging settings. Top: Image acquisition using a portable decoder (Apple iPhone $4 \mathrm{~S}, \times 20$ objective). Middle and bottom: Acquired image on exposure to $1 \mathrm{~W} 980 \mathrm{~nm}$ laser excitation (middle) and in the absence of NIR excitation (bottom), reproduced from ref. [14]

decoding false-alarm rate $\left(<10^{-9}\right) \cdot{ }^{14)}$

An initial set of UCNs 1-9, which were bright and unique upconversion nanoparticles, were synthesized through the hydro thermal reaction by adjusting the relative dopant concentrations of the ions $\mathrm{Yb}^{3+}, \mathrm{Er}^{3+}$, and $\mathrm{Tm}^{3+}$ in the reaction premix, which could be distinguished by the naked eye after a $980 \mathrm{~nm}$ NIR excitation. Fig. 8A illustrates integration of UCNs into polymer microparticles using stop-flow lithography (SFL). Two different kinds of particle monomer chemistries were explored, namely poly(urethane) acrylate
(PUA) for temperature- and chemical-resistant microparticles and poly(ethylene glycol) diacrylate (PEGDA) for biocompatibility. Integration with hydrophobic PUA or hydrophilic PEGDA particles requires rational surface chemistry. The monomer solution (PUA or PEGDA) with surface-modified UCNs was photopolymerized through illumination with mask-patterned ultraviolet light $(365 \mathrm{~nm})$. By embedding distinct UCNs within polymer microparticles to form a stripe-like emission feature consisting of up to 6 stripes, encoding capacities in excess of 1 million can be achieved. 
This high-throughput particle synthesis provided stripe-like patterned multicolor barcodes with a single-particle encoding capacity of $\mathrm{C}^{\mathrm{S}}$ for asymmetric particles and $\mathrm{C}^{\mathrm{S}} / 2$ for symmetric particles, where $\mathrm{C}$ is the number of UCN "colors" and $\mathrm{S}$ is the number of microparticle "stripes". This intuitive coding motif scale can increase rapidly with incremental changes to either distinguishable spectral signaturesUCN "colors" by adjusting $\mathrm{Yb}^{3+} / \mathrm{Er}^{3+} / \mathrm{Tm}^{3+}$ ratios with no impact on decoding, or spatial features - microparticle "stripes" by the additional stripe.

Figure 8B and Fig. 1B (top) show the extraordinary flexibility and practical utility of this universal architecture when utilized as covert labelling barcodes over a range of complex products including pharmaceutical packaging, credit cards, curved ceramic objects, reproduced artwork, high-temperature-cast polystyrene, and currency. The durable anti-counterfeiting labels can withstand extreme conditions of plastics engineering processes such as high-temperature casting and lamination. The covert labelling with a virtually unlimited encoding capacity of $\left(\mathrm{C}^{\mathrm{S}}\right)^{\mathrm{N}}$ for asymmetric and $\left(\mathrm{C}^{\mathrm{S}} / 2\right)^{\mathrm{N}}$ for symmetric particles $(\mathrm{N}$ : the number of particles deposited) can efficiently identify an object.

Notably, a straightforward portable charge-coupled device (CCD)-based decoding was presented here. The portable decoder consisted of a mobile phone adapter (Apple iPhone $4 \mathrm{~S})$ and $\mathrm{a} \times 20$ objective lens. Images of prepared stripeslike barcodes were captured using the portable CCD decoder and loaded into a software (Mathworks, Natick MA) to be defined using the detection algorithm. Implementation of quantitative decoding with the designed portable apparatus was straightforward as it utilized the same central components (CCD detector and magnification) as those of the microscope-based instrumentation. It was demonstrated that the covert multiparticle barcoding could be decoded readily even in complex surface conditions such as a blister pack or curved surface.

\subsection{Binary temporal upconversion code with core- shell structure}

More recently, versatile nanoplatforms with a core-shell structure combining emission color and lifetime modalities have proven especially useful for high-density information storage and multilevel anti-counterfeiting. The precisely controlled core-shell structure can induce excitation under various irradiation wavelengths..$^{27,61)}$

In 2017, Liu et al. developed binary temporal codes for lifetime-based data encoding by integrating the long-lived upconversion emission of transition metal ions $\mathrm{Mn}^{2+}$ and relatively short-lived lanthanide emission decay. ${ }^{27)}$ With well-controlled core-shell structures, the nanoparticles could be excited under both $980 \mathrm{~nm}$ and $808 \mathrm{~nm}$ irradiations. The prepared $\mathrm{Mn}^{2+}$-doped nanoparticles allow a high throughput rate of authentication, and the emission decay was distinguishable even by the naked eye without using any timegated decoding instrumentation.

The multilayer nanoparticles were designed to have a long-lived upconversion core and short-lived upconversion shells. Hexagonal-phase $\mathrm{NaGdF}_{4}: \mathrm{Mn}\left(30 \mathrm{~mol}^{\circ}\right)$ and $\mathrm{NaGdF}_{4}$ :

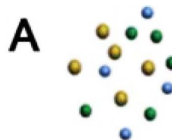

Hydrothermal Reaction

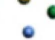
$200{ }^{\circ} \mathrm{C}, 8 \mathrm{~h}$

$200^{\circ} \mathrm{C}, 8 \mathrm{~h}$

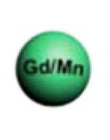

(1) Coprecepitation method $290{ }^{\circ} \mathrm{C}, 1.5 \mathrm{~h}$

(2) Thermal decomposition method $290{ }^{\circ} \mathrm{C}, 0.5 \mathrm{~h}$

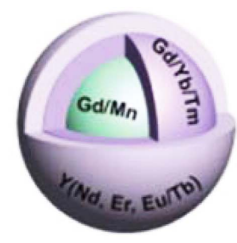

Multilayer nanoparticle

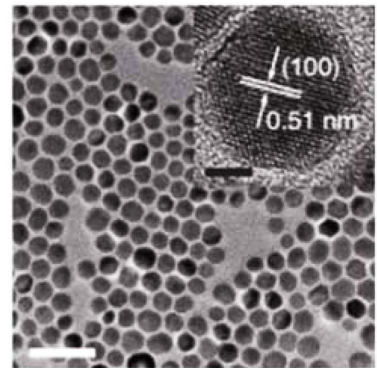

B

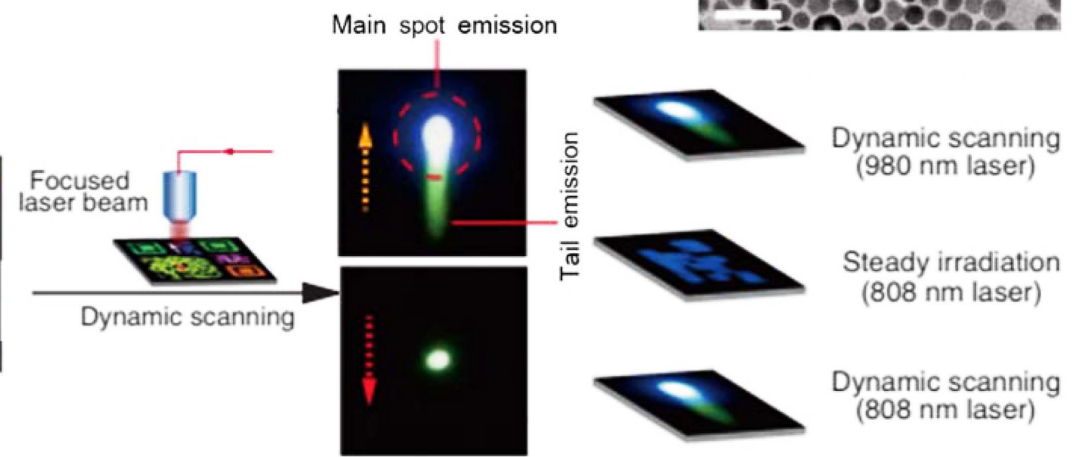

Fig. 9. A. Procedures used for the preparation of hexagonal-phase $\mathrm{NaGdF}_{4}: \mathrm{Mn}(30 \mathrm{~mol} \%) @ \mathrm{NaGdF}_{4}: \mathrm{Yb}_{\mathrm{Tm}}(49 / 1 \mathrm{~mol} \%) @ \mathrm{NaYF}_{4}$ multilayer nanoparticles (left) and TEM image of the as-prepared upconversion nanoparticles, scale bar, $50 \mathrm{~nm}$. (Inset: high-resolution TEM image of a single core-shell-shell nanoparticle, scale bar, $5 \mathrm{~nm}$ ) (right). B. Multilevel anti-counterfeiting application with $\mathrm{Mn}^{2+}$-activated core-shell nanoparticles. General design of the $2 \mathrm{D}$ patterns made with nanoparticles of different composition and emission profiles of the pattern recorded under different irradiation conditions, nanoparticle used for generating the pattern: $\mathrm{NaGdF}_{4}: \mathrm{Mn}$ (30 mol\%)@NaGdF $: \mathrm{Yb} / \mathrm{Tm}$ (49/1 mol\%)@NaYF$: \mathrm{Nd}$ (20 mol\%), reproduced from ref. [27] 
$\mathrm{Yb} / \mathrm{Tm}(49 / 1 \mathrm{~mol} \%)$ are generated as the core and first shell layer, respectively, to enable the long-lived $\mathrm{Mn}^{2+}$ upconversion emission. Considering that the lifetime of a $\mathrm{Mn}^{2+}$ emission (39 ms) is approximately 65 times longer than that of a $\mathrm{Tm}^{3+}$ emission, the emission can be detected by the naked eye. In addition, the core-shell structure of multilayer nanoparticles can also contribute to retaining the long lifetime of $\mathrm{Mn}^{2+}$ emission by avoiding the back-energy transfer from $\mathrm{Mn}^{2+}$ to $\mathrm{Yb}^{3+}$ due to separation. Succeeding layers $\mathrm{NaYF}_{4}$ or $\mathrm{NaYF}_{4}: \mathrm{A}(\mathrm{A}: \mathrm{Nd}, \mathrm{Eu}, \mathrm{Eu} / \mathrm{Tb}$ or $\mathrm{Tb})$ can be conveniently passivated in support of tuning the short-lived lanthanide emission color, while preserving the long-lived emission of $\mathrm{Mn}^{2+}$.

The multilayer nanoparticles were synthesized as follows (Fig. 9A). First, hexagonal-phase $\mathrm{NaGdF}_{4}: \mathrm{Mn}$ (30 mol\%) core nanoparticles were prepared by a hydrothermal method. Next, epitaxial growth of $\mathrm{NaYF}_{4}: \mathrm{Yb} / \mathrm{Tm}$ and $\mathrm{NaYF}_{4}$ layers onto the cores was enabled by a coprecipitation reaction at $290^{\circ} \mathrm{C}$ for $1.5 \mathrm{~h}$, followed by thermal decomposition at $290^{\circ} \mathrm{C}$ for $0.5 \mathrm{~h}$. The TEM image in Fig. 9A shows the upconversion nanoparticles with a particle size of $17 \mathrm{~nm}$. These were further doped with $\mathrm{Eu}^{3+}$ or $\mathrm{Er}^{3+}$ in the presence of a $\mathrm{NaYF}_{4}$ inert shell layer to enrich the variety of the short-lived upconversion emission colors. The epitaxially grown shell of $\mathrm{NaYF}_{4}: \mathrm{Nd}\left(20\right.$ mol\%) on $\mathrm{NaGdF}_{4}: \mathrm{Mn}$ (30 mol\%)@ NaGdF4: $\mathrm{Yb} / \mathrm{Tm}$ (49/1 mol\%) nanoparticles could generate $\mathrm{Mn}^{2+}$ upconversion emission at $808 \mathrm{~nm}$ because of the energy transfer from $\mathrm{Nd}^{3+}$ to $\mathrm{Yb}^{3+}$.

As a proof-of-concept, the authors demonstrated that the $\mathrm{Mn}^{2+}$-doped multilayer nanoparticles were suitable for multilevel anti-counterfeiting applications on reproduced artwork as binary temporal codes. 2D-converted patterns were stamped by $\mathrm{Mn}^{2+}$-activated core-shell nanoparticles of different composition and colloidal $\mathrm{NaYF}_{4}: \mathrm{Yb} / \mathrm{Er}(20 / 2 \mathrm{~mol} \%)$ nanoparticles as a control (Fig. 9B). Steady irradiation at $980 \mathrm{~nm}\left(6 \mathrm{~W} \mathrm{~cm}^{-2}\right)$ led to multicolor patterns, while dynamic scanning of the identical patterns with a focused laser beam $\left(64 \mathrm{~W} \mathrm{~cm}^{-2}\right)$ yielded a different result. Unlike only a main green spot of emission emerging from the pattern stamped by purely lanthanide-doped nanoparticles, the as-prepared multilayer nanoparticles showed a bright main spot of emission with an additional tailed emission in green. The color of the main spot was varied with different doping compositions. Additionally, patterns prepared with $\mathrm{Nd}^{3+}$-sensitized nanoparticles were found to have similar emission features under excitation at either $980 \mathrm{~nm}$ or $808 \mathrm{~nm}$.

\section{Conclusions}

The combination of advanced ceramic materials science and information technology allows access to various emerging strategies for info-convergence applications. It is particularly suitable for item-level tagging and labelling identification, nano-forensics, tracking-and-traceability management, anti-counterfeiting, data storage, and even communication.
Although only two types of info-convergence ceramic nanosystems, ceramic nanohybrids with DNA codes and ceramic nanoparticle upconversion codes are covered in this review, each serves the role of either a coding support or coding substance. With respect to DNA@ $\mathrm{SiO}_{2}$ and DNA@LDH nanohybrid codes, silica and $\mathrm{LDH}$ ceramic materials can act as protection layers for DNA against physical, chemical, and biological degradation. The code carriers can be applied to tangible products and are also responsible for surface functionality, as well as timed and on-demand recoverability for DNA tags. In the case of ceramic upconversion codes, lanthanide-doped UCNs are efficient for anti-counterfeiting applications due to the large encoding capacities and enhanced quantum conversion, which could be realized through manipulation of composition, life time, morphology, structural configuration, and excitation.

The approaches highlighted in this review will provide further basis for info-convergence ceramic nanosystems in multidisciplinary science. It is believed that these ceramicbased novel materials have the potential to enhance the performance of code systems to a new level and enable a wide variety of applications.

\section{Acknowledgments}

This work was supported by the National Research Foundation of Korea (NRF) grant funded by the Korea government (MSIT) (No. NRF-2019R1G1A1006582).

\section{REFERENCES}

1. D. H. Park, S. J. Hwang, J. M. Oh, J. H. Yang, and J. H. Choy, "Polymer-Inorganic Supramolecular Nanohybrids for Red, White, Green, and Blue Applications," Prog. Polym. Sci., 38 [10-11] 1442-86 (2013).

2. J. M. Oh, D. H. Park and J. H. Choy, "Integrated Bio-Inorganic Hybrid Systems for Nano-forensics," Chem. Soc. Rev., 40 583-95 (2011).

3. D. H. Park, C. J. Han, Y. G. Shul, and J. H. Choy, "Avatar DNA Nanohybrid System in Chip-on-a-Phone," Sci. Rep., 4, Article number: 4879 (2014).

4. H. Palneedi, M. Peddigari, G-T. Hwang, D-Y. Jeong, and J. Ryu, "High-Performance Dielectric Ceramic Films for Energy Storage Capacitors: Progress and Outlook," Adv. Funct. Mater, 28 [42] 1803665 (2018).

5. D. H. Park, J. E. Kim, J. M. Oh, Y. G. Shul, and J. H. Choy, "DNA Core@Inorganic Shell," J. Am. Chem. Soc., 132 [47] 16735-36 (2010).

6. J. H. Choy, S. Y. Kwak, J. S. Park, Y. J. Jeong, and J. Portier, "Intercalative Nanohybrids of Nucleoside Monophosphates and DNA in Layered Metal Hydroxide," $J$. Am. Chem. Soc., 121 [6] 1399-400 (1999).

7. D. H. Park, J. Cho, O. J. Kwon, C. O. Yun, and J. H. Choy, "Biodegradable Inorganic Nanovector: Passive versus Active Tumor Targeting in siRNA Transportation," Angew. Chem. Int. Ed., 55 [14] 4582-86 (2016).

8. E. D. Wachsman and K. T. Lee, "Lowering the Tempera- 
ture of Solid Oxide Fuel Cells," Science, 334 [6058] 935-39 (2011).

9. S. Ishihara, P. Sahoo, K. Deguchi, S. Ohki, M. Tansho, T. Shimizu, J. Labuta, J. P. Hill, K. Ariga, K. Watanabe, Y. Yamauchi, S. Suehara, and N. Iyi, "Dynamic Breathing of $\mathrm{CO}_{2}$ by Hydrotalcite," J. Am. Chem. Soc., 135 [48] 1804043 (2013).

10. K. Schwab, "The Fourth Industrial Revolution," World Economic Forum, 2016.

11. M. C. Roco and W. S. Bainbridge, "Converging Technologies for Improving Human Performance: Nanotechnology, Biotechnology, Information Technology and Cognitive Science," National Science Foundation, 2003.

12. G. M. Church, Y. Gao, and S. Kosuri, "Next-Generation Digital Information Storage in DNA," Science, 337 [6102] 1628 (2012).

13. F. Akram, I. Haq, H. Ali, and A. T. Laghari, "Trends to Store Digital Data in DNA: An Overview," Mol. Biol. Rep., 45 [5] 1479-90 (2018).

14. J. Lee, P. W. Bisso, R. L. Srinivas, J. J. Kim, A. J. Swiston, and P. S. Doyle, "Universal Process-Inert Encoding Architecture for Polymer Microparticles," Nat. Mater., 13 524-29 (2014).

15. R. N. Grass, R. Heckel, M. Puddu, D. Paunescu, and W. J. Stark, "Robust Chemical Preservation of Digital Information on DNA in Silica with Error-Correcting Codes," Angew. Chem. Int. Ed., 54 [8] 2552-55 (2015).

16. J. H. Choy, J. M. Oh, M. Park, K. M. Sohn, and J. W. Kim, "Inorganic-Biomolecular Hybrid Nanomaterials as a Genetic Molecular Code System," Adv. Mater., 16 [14] 1181-84 (2004).

17. D. Paunescu, M. Puddu, J. O. B. Soellner, P. R. Stoessel, and R. N. Grass, "Reversible DNA Encapsulation in Silica to Produce ROS-Resistant and Heat-Resistant Synthetic DNA 'Fossils'," Nat. Protoc., 8 [12] 2440-48 (2013).

18. D. H. Park and J. H. Choy, "Emerging Strategies in Infohybrid Systems," Eur. J. Inorg. Chem., 2012 [32] 5145-53 (2012).

19. D. Paunescu, C. A. Mora, L. Querci, R. Heckel, M. Puddu, B. Hattendorf, D. Günther, and R. N. Grass, "Detecting and Number Counting of Single Engineered Nanoparticles by Digital Particle Polymerase Chain Reaction," ACS Nano, 9 [10] 9564-72 (2015).

20. M. Puddu, D. Paunescu, W. J. Stark, and R. N. Grass, "Magnetically Recoverable, Thermostable, Hydrophobic DNA/Silica Encapsulates and Their Application as Invisible Oil Tags," ACS Nano, 8 [3] 2677-85 (2014).

21. M. S. Bloch, D. Paunescu, P. R. Stoessel, C. A. Mora, W. J. Stark, and R. N. Grass, "Labeling Milk along Its Production Chain with DNA Encapsulated in Silica," J. Agric. Food Chem., 62 [43] 10615-20 (2014).

22. B. Duong, H. L. Liu, L. Y. Ma, and M. Su, "Covert Thermal Barcodes Based on Phase Change Nanoparticles," Sci. Rep., 4, 5170 (2014).

23. M. Wang, B. Duong, H. Fenniri, and M. Su, "Nanomaterials-based Barcode," Nanoscale, 7 [26] 11240-47 (2015).

24. S. H. Wen, J. J. Zhou, K. Z. Zheng, A. Bednarkiewicz, X. G. Liu, and D. Y. Jin, "Advances in Highly Doped Upconversion Nanoparticles," Nat. Commun., 92415 (2018).
25. B. Zhou, B. Y. Shi, D. Y. Jin, and X. G. Liu, "Controlling Upconversion Nanocrystals for Emerging Applications," Nat. Nanotechnol., 10 [11] 924-36 (2015).

26. Y. Q. Lu, J. B. Zhao, R. Zhang, Y. J. Liu, D. M. Liu, E. M. Goldys, X. S. Yang, P. Xi, A. Sunna, J. Lu, Y. Shi, R. C. Leif, Y. J. Huo, J. Shen, J. A. Piper, J. P. Robinson, and D. Y. Jin, "Tunable Lifetime Multiplexing Using Luminescent Nanocrystals," Nat. Photonics, 8 32-6 (2014).

27. X. W. Liu, Y. Wang, X. Y. Li, Z. G. Yi, R. R. Deng, L. L. Liang, X. J. Xie, D. T. B. Loong, S. Y. Song, D. Y. Fan, A. H. All, H. J. Zhang, L. Huang, and X. G. Liu, "Binary Temporal Upconversion Codes of $\mathrm{Mn}^{2+}$-Activated Nanoparticles for Multilevel Anti-Counterfeiting," Nat. Commun., 8 899 (2017).

28. M. L. You, M. Lin, S. R. Wang, X. M. Wang, G. Zhang, Y. Hong, Y. Q. Dong, G. R. Jin, and F. Xu, "Three-Dimensional Quick Response Code Based on Inkjet Printing of Upconversion Fluorescence Nanoparticles for Drug AntiCounterfeiting," Nanoscale, 8 [19] 10096-104 (2016).

29. K. Ming, J. S. Kim, M. J. Biondi, A. Syed, K. Chen, A. Lam, M. Ostrowski, A. Rebbapragada, J. J. Feld, and W. C. W. Chan, "An Integrated Quantum Dot Barcode Smartphone Optical Device for Wireless Multiplexed Diagnosis of Infected Patients," ACS Nano, 9 [3] 3060-74 (2015).

30. L. Chen, C. Lai, R. Marchewka, R. M. Berry, and K. C. Tam, "CdS Quantum Dot-Functionalized Cellulose Nanocrystal Films for Anti-Counterfeiting Applications," Nanoscale, 8 [27] 13288-96 (2016).

31. M. Y. Han, X. H. Gao, J. Z. Su, and S. Nie, "Quantum-DotTagged Microbeads for Multiplexed Optical Coding of Biomolecules," Nat. Biotechnol., 19 [7] 631-35 (2001).

32. G. Wang, Y. K. Leng, H. J. Dou, L. Wang, W. W. Li, X. B. Wang, K. Sun, L. S. Shen, X. L. Yuan, J. Y. Li, K. Sun, J. S. Han, H. S. Xiao, and Y. Li, "Highly Efficient Preparation of Multiscaled Quantum Dot Barcodes for Multiplexed Hepatitis B Detection," ACS Nano, 7 [1] 471-81 (2013).

33. H. M. Nam, K. J. Song, D. G. Ha, and T. S. Kim, "Inkjet Printing Based Mono-layered Photonic Crystal Patterning for Anti-counterfeiting Structural Colors," Sci. Rep., 6 30885 (2016).

34. H. S. Lee, T. S. Shim, H. R. Hwang, S.-M. Yang, and S.-H. Kim, "Colloidal Photonic Crystals toward Structural Color Palettes for Security Materials," Chem. Mater., 25 [13] 2684-90 (2013).

35. C. T. Clelland, V. Risca, and C. Bancroft, "Hiding Messages in DNA Microdots," Nature, 399 533-34 (1999).

36. N. Goldman, P. Bertone, S. Y. Chen, C. Dessimoz, E. M. LeProust, B. Sipos, and E. Birney, "Towards Practical, High-Capacity, Low-Maintenance Information Storage in Synthesized DNA," Nature, 494 [7435] 77-80 (2013).

37. J. P. L. Cox, "Long-Term Data Storage in DNA," Trends Biotechnol., 19 [7] 247-50 (2001).

38. Y. G. Li, Y. T. H. Cu, and D. Luo, "Multiplexed Detection of Pathogen DNA with DNA-based Fluorescence Nanobarcodes," Nat. Biotechnol., 23 885-89 (2005).

39. G. M. Church, "Methods of Storing Information Using Nucleic Acids"; U.S. Patent 9,996,778, 2018.

40. J. Davis, "Microvenus," Art J., 55 70-4 (1996). 
41. T. Lindahl, "Instability and Decay of the Primary Structure of DNA," Nature, 362 [6422] 709-15 (1993).

42. R. Yin, D. Zhang, Y. Song, B. Z. Zhu, and H. Wang, "Potent DNA Damage by Polyhalogenated Quinones and $\mathrm{H}_{2} \mathrm{O}_{2}$ via a Metal-Independent and Intercalation- Enhanced Oxidation Mechanism," Sci. Rep. 31269 (2013).

43. J. M. Oh, S. Y. Kwak, and J. H. Choy, "Intracrystalline Structure of DNA Molecules Stabilized in the Layered Double Hydroxide," J. Phys. Chem. Solids, 67 [5-6] 102831 (2006).

44. T. W. Kim, I. Y. Kim, D. H. Park, J. H. Choy, and S. J. Hwang, "Highly Stable Nanocontainer of APTES-Anchored Layered Titanate Nanosheet for Reliable Protection/ Recovery of Nucleic Acid," Sci. Rep., 621993 (2016).

45. P. X. Wu, W. Li, Y. J. Zhu, Y. N. Tang, N. W. Zhu, and C. L. Guo, "The Protective Effect of Layered Double Hydroxide against Damage to DNA Induced by Heavy Metals," Appl. Clay Sci., 100 76-83 (2014).

46. D. Paunescu, C. A. Mora, M. Puddu, F. Krumeich, and R. N. Grass, "DNA Protection against Ultraviolet Irradiation by Encapsulation in a Multilayered $\mathrm{SiO}_{2} / \mathrm{TiO}_{2}$ Assembly," J. Mater. Chem. B, 2 [48] 8504-9 (2014).

47. W. D. Chen, A. X. Kohll, B. H. Nguyen, J. Koch, R. Heckel, W. J. Stark, L. Ceze, K. Strauss, and R. N. Grass, "Combining Data Longevity with High Storage CapacityLayer-by-Layer DNA Encapsulated in Magnetic Nanoparticles," Adv. Funct. Mater., 29 [28] 1901672 (2019).

48. M. A. Palacios, E. Benito-Peña, M. Manesse, A. D. Mazzeo, C. N. Lafratta, G. M. Whitesides, and D. R. Walt, "InfoBiology by Printed Arrays of Microorganism Colonies for Timed and On-Demand Release of Messages," Proc. Natl. Acad. Sci., 108 [40] 16510-4 (2011).

49. S. W. Thomas III, R. C. Chiechi, C. N. LaFratta, M. R. Webb, A. Lee, B. J. Wiley, M. R. Zakin, D. R. Walt, and G. M. Whitesides, "Infochemistry and Infofuses for the Chemical Storage and Transmission of Coded Information," Proc. Natl. Acad. Sci., 106 [23] 9147-50 (2009).

50. D. H. Park, G. Choi, and J. H. Choy, "Bio-Layered Double Hydroxides Nanohybrids for Theranostics Applications," pp. 137-74 in Photofunctional Layered Materials, Structure and Bonding, 2015.
51. S. M. Paek, J. M. Oh, and J. H. Choy, "A Lattice-Engineering Route to Heterostructured Functional Nanohybrids," Chem. Asian. J., 6 [2] 324-38 (2011).

52. G. Mishra, B. Dash, and S. Pandey, "Layered Double Hydroxides: A Brief Review from Fundamentals to Application as Evolving Biomaterials," Appl. Clay Sci., 153 172-86 (2018).

53. J. M. Oh, D. H. Park, S. J. Choi, and J. H. Choy, "LDH Nanocontainers as Bio-Reservoirs and Drug Delivery Carriers," Recent Pat. Nanotechnol., 6 [3] 200-17 (2012).

54. J. H. Choy, S. Y. Kwak, Y. J. Jeong, and J. S. Park, "Inorganic Layered Double Hydroxides as Nonviral Vectors," Angew. Chem. Int. Ed., 39 [22] 4042-45 (2000).

55. J. M. Oh, T. T. Biswick, and J. H. Choy, "Layered Nanomaterials for Green Materials," J. Mater. Chem., 19 [17] 2553-63 (2009).

56. S. Shikha, T. Salafi, J. T. Cheng, and Y. Zhang, "Versatile Design and Synthesis of Nano-Barcodes," Chem. Soc. Rev., 46 [22] 7054-93 (2017).

57. X. Qin, J. H. Xu, Y. M. Wu, and X. G. Liu, "Energy-Transfer Editing in Lanthanide-Activated Upconversion Nanocrystals: A Toolbox for Emerging Applications," ACS Cent. Sci., 5 [1] 29-42 (2019).

58. Y. H. Zhang, L. X. Zhang, R. Deng, J. Tian, Y. Zong, D. Y. Jin, and X. G. Liu, "Multicolor Barcoding in a Single Upconversion Crystal," J. Am. Chem. Soc., 136 [13] 489396 (2014).

59. H. C. Liu, M. K. G. Jayakumar, K. Huang, Z. Wang, X. Zheng, H. Ågren, and Y. Zhang, "Phase Angle Encoded Upconversion Luminescent Nanocrystals for Multiplexed Applications," Nanoscale, 9 1676-86 (2017).

60. H. Dong, L.-D. Sun, W. Feng, Y. Y. Gu, F. Y. Li, and C.-H. Yan, "Versatile Spectral and Lifetime Multiplexing Nanoplatform with Excitation Orthogonalized Upconversion Luminescence," ACS Nano, 11 [3] 3289-97 (2017).

61. D. L. Zhou, D. Y. Li, X. Y. Zhou, W. Xu, X. Chen, D. L. Liu, Y. S. Zhu, and H. W. Song, "Semiconductor Plasmon Induced Upconversion Enhancement in $\mathrm{mCu}_{2-\mathrm{x}} \mathrm{S}_{\mathrm{S}} \mathrm{SiO}_{2} @ \mathrm{Y}_{2} \mathrm{O}_{3}: \mathrm{Yb}^{3+}$, $\mathrm{Er}^{3+}$ Core-Shell Nanocomposites," ACS Appl. Mater. Interfaces, 9 [40] 35226-33 (2017). 